\title{
TEACHING LARGE STUDENT COHORTS IN SECOND LIFE Scalability Issues and Student Satisfaction in a Virtual World
}

\author{
Marc Conrad, David Pike, Paul Sant, Catherine Nwafor \\ Department of Computer Science and Technology, University of Bedfordshire, Park Square, Luton, United Kingdom \\ marc.conrad@beds.ac.uk,david.pike@beds.ac.uk,paul.sant@beds.ac.uk,nwafor_kate@yahoo.com
}

Keywords: $\quad$ Second Life, Virtual Worlds, Student Activities

Abstract: There are high expectations on Second Life, a multi-user interactive virtual environment, to play a prominent
role in higher education in the future. Across universities worldwide many projects aim to engage students
in a variety of activities related to Second Life. However typically the number of students participating in
those projects is small and the use of Second Life is an optional addition to the syllabus. We present two
activities, conducted in 2007 and 2008 where Second Life has been used as an integral, non voluntarily part
of an assignment in project management. Feedback from the 200 participants has been collected in the form
of a questionnaire and interviews. Our results show that students have found the experience mostly positive,
or, at least, didn't object to it. However technical and administrative problems have been identified that still
question the suitability of Second Life for a smooth provision of these activities on a large scale.

\section{INTRODUCTION}

Second Life (Linden Lab, 2003) is an online three dimensional virtual world with an advanced way of building, interaction, socialization, communication, collaboration and networking. Businesses and institutions of various backgrounds such as IBM, Toyota, Reuters, BBC or Adidas enjoy a virtual presence in Second Life (Salomon, 2007). At the time of writing (November 2008) Second Life statistics records over $1,000,000$ users "logged in last 60 days" and more than 60,000 users "online now". In the educational sector it is often seen as a modern method of teaching and learning online. The huge expectations on Second Life as an educational tool manifests itself in statements such as "As students expectations rise, educational institutions will have to find ways of providing a mass-customised service, and virtual world technologies provide a cost-effective way of providing individualised support in a superior way to the current Web 2.0 platforms such as Blackboard or Moodle.” (Kingsley, 2007)

However current studies of student behavior in Second Life are pilots with small student cohorts (Sanchez, 2007; Ritzema and Harris, 2008) and of- ten optional in the student's course diet. In contrast our study seeks to answer the question of how such activities scale to large student cohorts in a situation where Second Life constitutes a mandatory and integral assessment part of the module syllabus.

In doing so we not only question the validity of the statement quoted above but also are able to demonstrate the problems arising with scaling Second Life to large cohorts. The result could be summarized as follows. While students are indeed willing and ready to accept the inclusion of Second Life as part of their learning experience, the technical underpinnings of Second Life itself need to improve before we can expect its widespread use in teaching.

The paper is organized as follows. First we give an overview about the virtual presence of the University of Bedfordshire where this study has been carried out and put this into the wider context of educational activities in Second Life. This is followed in Section 3 by a description of the tasks given to the students. In total 200 students have been "sent" to Second Life. Evidence of their experience has been gathered via a questionnaire and interviews in addition to anecdotal observations. This evidence is presented in Section 4 followed by the conclusions in Section 5 . 


\section{UNIVERSITIES IN SECOND LIFE}

Second Life is an online virtual environment offering opportunities for interaction between many different sections of the world-wide community. There are several different types of activities that can be undertaken within the Second Life "grid": interacting with other users (known as avatars), buying and selling objects such as clothing, participating in or attending live events. Utilizing Second Life and taking on the role of an avatar is free. Therefore from an educator's point of view, it is possible to discover areas where opportunities for students' development can take place. Many educational establishments and commercial bodies have a presence within Second Life and it is clearly becoming a point of interest for the larger web-community.

Activities in the UK are well documented (Kirriemuir, 2008) and show a great variety: Projects range from small student driven projects up to large developments across nine Second Life "islands". Many universities have externally funded research projects in Second Life. Casually browsing the Internet and Second Life itself suggests many similar activities from universities all over the world.

(Ritzema and Harris, 2008) attempted to evaluate the use of Second Life as a tool for facilitating distance learning. The team rebuilt real life examples from a computing laboratory in the Second Life grid for students to experiment with. The group in this case was relatively small (fourteen individuals), but the feedback was extremely positive and indicated that many of the students found that the online activity enabled them to better understand the laboratory work.

(Sanchez, 2007) reports on the social and technical issues in the context of a student activity involving a focus group of eighteen students. There the picture is less positive and a number of both social and technical issues are highlighted.

Anecdotal experience gathered from various personal discussions with educators in Second Life seems to indicate that typically the use of Second Life at universities is an initiative of a small number of individuals, usually teachers, that in addition to their teaching activities (in the context of their Second Life activities) assume the roles of technical and administrative support. Often the use of that "game" in teaching is merely tolerated by senior administrative management and (in the best case) not been hindered by technical support. This is reminiscent to the early days of the Internet where educators who wanted to make their teaching material available electronically had to adopt the additional role of their own web master.

The situation at the University of Bedfordshire is much better. Land in Second Life has been acquired by the Teaching \& Learning Support Department and championed by the technical support. Innovative teaching using Second Life is explicitly encouraged. We are going to show however that even in such a seemingly optimal environmental and organizational context the use of Second Life as a mandatory part of a student assignment is not without problems. Evidence has been gathered from two assignments involving 200 students in total. While the students' feedback is generally positive, technical difficulties that arise from the inherent workings of Second Life itself prevail, or to put it more bluntly: While students are ready for an assignment of that style, Second Life itself is not (yet).

We want however add a caveat: Second Life provides a whole plethora of opportunities for universities. This paper is not meant to question such activities in principle. In particular it may well be suitable for individual projects of creative and interested students in areas such as art, psychology, computer science or architecture. However the scalability of such projects to a large cohort of students that a priori cannot be assumed to have any specific aptitude towards virtual environments is questioned here.

\section{THE TASKS ASSIGNED TO THE STUDENTS}

\subsection{Context of the assignment}

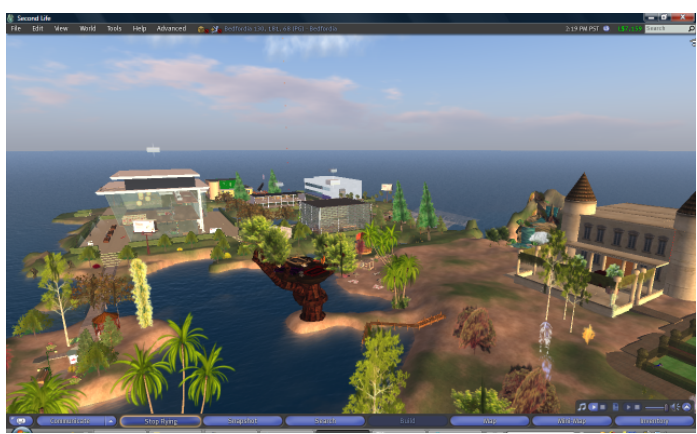

Figure 1: View over Bedfordia (front) and the University of Bedfordshire (back) in Second Life.

The location of the student activities that we are going to describe in the following sections took place at the island "Bedfordia" owned by the department of Teaching and Learning of the University of Bedfordshire, For clarity it should be noted that the university 
also owns a second adjacent island named "University of Bedfordshire" which is primarily used for marketing purposes. In particular while the "University of Bedfordshire" island has been designed to give a look and feel of the real university by featuring characteristic university buildings such as a library or student union, the island of Bedfordia has been landscaped by a skilled builder to stimulate creative activities. It features atmospheric structures such as lakes, woodlands, a tree house and a swimming pool (Figure 1). The Teaching and Learning island Bedfordia has a size of 32560 sq. m. For the assignment an area of about 5632 sq. m. has been made available as a building area - "sandbox" - for the students. The use of Second Life has been championed as well by the university's Information Systems Department so that there have been no principal issues to be resolved concerning firewalls, blocked ports or Second Life client installations on student machines (difficulties that are often encountered at other universities). In summary it can be said that the environmental and technical conditions have been optimal to run the learning activities described in the next section.

\subsection{Pilot Activity, Autumn 2007}

In 2007 the provision of the Second Life island by the University of Bedfordshire was brought to the attention to the teaching team of the undergraduate 3rd year module "IT Project Management". At that time Second Life has been accessible from inside the university via client installations in a lab specialized in computer graphics. Given this availability a decision was made to pilot the use of Second Life to a larger cohort of students. In that module 84 students were enrolled.

In previous years the assessment of the project management module already contained an element that focuses on team cohesion and human interaction. Students were randomly assigned into teams and given access to a team-owned discussion board. The core task for the students was to organize social meetings in order to "improve the team coherence". The marks were based on the students evaluation of those meetings. For more details (without the Second Life context) please see (Conrad et al., 2006) where the assignment and learning outcomes are presented and the relevance to cultural profiles of teams is discussed.

In 2007 this activity has been altered by requiring the students to meet virtually in Second Life. Because introducing students to the specific demands of "virtual teams" has already been part of the syllabus in previous years the use of Second Life would blend in naturally. The students were given the fol- lowing case study (in the following all emphasized text denotes a direct quotation from the assignment sheet the students received): "BedTime Books Ltd wants to set up a (virtual) branch in Second Life (see http://secondlife.com ). BedTime Books' branch should be located near the University of Bedfordshire at the island Bedfordia. Your company has no previous experience with virtual worlds. For this project BedTime Books has assigned you to a project team of 7 or 8 people. As the team members come from different locations [...] a group discussion board has been set up [...] to enhance communication." The notion of "different locations" has been simulated by sourcing the groups from different practical sessions meaning that there was a priori no default time slot in the week where students can meet either virtually or really. This must be negotiated within the student group. The students had to work against the following two goals:

- To form a coherent team that could actually start with building the branch [...].

- To familiarize all team members with the virtual environment provided by Second Life, and in particular the island Bedfordia.

The meeting had to be evidenced by providing a screenshot and the whole process had later to be evaluated in an individual report. The activity concluded with the following note: "No particular help will be given from the tutors on how to use and interact with Second Life. To identify suitable resources such as tutorials is part of the task of the project team." As Second Life is designed in a way that it is usable by the general public and even more because the students have been enrolled in computing related degrees where an affinity towards the use of software can be assumed this approach seemed feasible. As a matter of fact the validity of the remark has not been questioned by any of the students.

The activity is essentially designed as an individual assessment in so far that marks are primarily not given on the group performance as a whole but rather based on the individual students' interactions and their reflection on those in the final report. A template for this report has been provided and we included an evaluative questionnaire on the experience of the students in Second Life. While the answers of this evaluation questionnaire have not been considered to be relevant for the students' grade they nevertheless allowed to gather the quantitative and qualitative feedback that informed the use of Second Life in the next assignment described in Section 3.3. For details on the results of this questionnaire see Section 4.3. From the 84 students enrolled in this activity around fifty filled in the questionnaire. 
The assignment helped to get an initial feeling about what it means to use Second Life as a tool in teaching and assessing students. In addition it helped to sort out some teething problems in deploying the necessary Second Life client software as a default application on the workstations so that it is accessible by the students.

\subsection{Building of a Showcase (Professional Project Management)}

Inspired by the positive experience in autumn 2007 as described in the previous section a decision was made to include Second Life in the assessment process of the postgraduate module "Professional Project Management" that run in spring 2008. In this module 114 students have been enrolled. The focus of this assessment is the successful application of a project management processes within a real-world environment. More specifically the following learning outcomes have been addressed in this activity:

- To understand the importance of team coherence in a professional (team based) project

- To clearly communicate in a variety of media at an advanced academic level

- To develop Key Skills in the areas of Performance Management and Presentation and Evaluation

- To apply a project management methodology within a real-world context.

At the start of the assignment students have been pre-assigned into teams of 4-6 people. It should be noted that this module is part of the syllabus of various different postgraduate awards in Computing at the University of Bedfordshire. As far as possible the teams have been assigned in a way so that all students in any particular team share the same award. This should provide a common basis to work on the project mandate that was described as follows (quote from the assignment sheet):

"You have been asked to work in a group of IT specialists to develop a set of products that can be used to educate the general public about your specialist area, e.g., Networking students will educate the general public on wireless and mobile networks; Computer Scientists will educate the general public on pervasive computing, and how computing is becoming an integral part of our lives; Generalists will educate the general public on the increasing use of E-commerce, and the security implications that this has."

Then the set of products to be developed is further described:
- "Poster [...]

- A wiki page [...]

- A Second Life showcase that would serve to raise the awareness of visitors of the virtual University of Bedfordshire to essential issues regarding your specialist area. This showcase will be presented to the Programme/Corporate Management (i.e. the module tutors) but should be designed and build in a way that it is accessible to the general public."

The assignment sheet than finally gave further direction on the processes to be used. Concerning Second Life the following paragraph was added:

"Second Life is accessible from the CIS labs (or, of course, from home). You have to register an account with Linden Labs at www.secondlife.com. No particular help will be given from the tutors on how to use and interact with Second Life. To identify suitable resources such as tutorials is part of the task of the project team and must hence be included in the project brief. A dedicated space to build up the Second Life showcase will be provided [...]. Please ensure to produce regular screenshots in order to document the progress of the project.

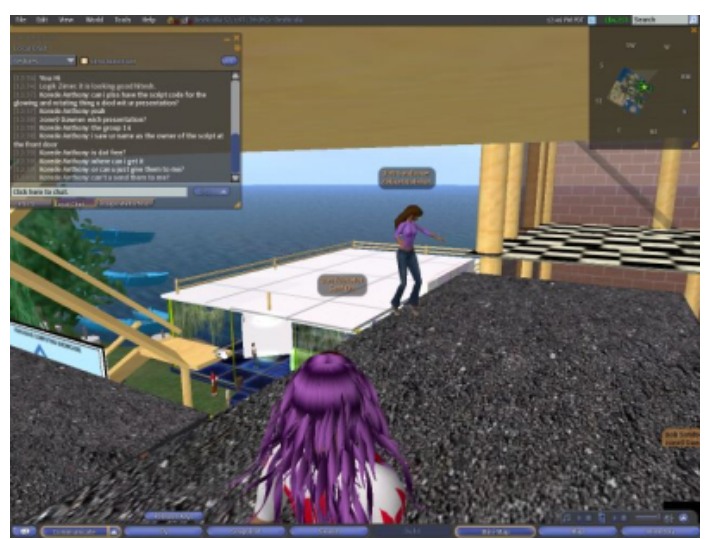

Figure 2: Students working on the assignment in Second Life.

Evidence on how this assignment has been perceived has been gathered by interviews with the students at the end of the course.

We want to point out here that Second Life has been introduced to the students as a platform for productivity and not as a means to communicate with each other remotely or as a place to have virtual meetings. Those features though have been mentioned as side effects in the lectures and practical sessions. 


\section{FEEDBACK FROM THE ACTIVITIES}

\subsection{Anecdotal Observations}

We start our discussion on feedback with reporting some of the students' reactions made at the beginning of the assignment or shortly after.

- Only one student of the second cohort challenged the tutor in questioning the use of Second Life in principle. Those concerns could be addressed by pointing out the relevance of virtual teams in locally distributed real life projects and also in hinting that Second Life is not a game but a social platform that is used for education also by other institutions throughout the UK and worldwide.

- Some students had difficulties with the term "showcase" used in the assignment. This has been addressed by reference to showcases of companies and other institutions in Second Life. As it was intended to give the project teams ownership in making their own design decisions it was abstained from giving step-by-step details on what should constitute an acceptable end result.

- The intention that no help was to be provided by the tutors was overoptimistic to say the least. While that approach was feasible in the much simpler undergraduate assignment as described in Section 3.2 it was felt that most students found the task to actually build in Second Life very challenging. Hence it was decided to start one of the lectures with a short fifteen minute long demonstration on how to actually build a simple poster in Second Life by starting with a slide in PowerPoint (saving the PowerPoint slide as png-file, uploading the file and applying the texture to a prim in Second Life). Actual building of the students in Second Life then started essentially after that demonstration. In addition some useful building tools have been provided in-world for the students to work with and individual help was given by the tutors (see below).

- Once students had completed the process of registering an avatar on Second Life they were required to send an instant message to an assigned member of staff so the student could be placed in a group with appropriate access to build and create objects. It was then decided to provide a minimal level of instruction for the students as we considered this to be an important part of each individual project's development. Tutors spent time with the students explaining the nature and abilities to manipulate objects in Second Life within the University's sandbox area. One of the voluntary residents on the Bedfordia island provided students with links to other areas and to textures and objects within Second Life.

\subsection{Questionnaire Evaluation of the Pilot Activity}

The following questionnaire has been distributed to the students after the activity:

In the second part of the assignment you have been asked to use Second Life. To help us to understand your experience with this new format better we would like you to answer the following questions.

1. On a scale of 1 (easiest) to 5 (hardest) how easy did you find it to to get into Second Life?

2. What things were difficult (if anything) about getting IN to Second Life?

3. On a scale of 1 (easiest) to 5 (hardest) - how easy did you find it to get to Bedfordia?

4. What things were difficult about getting to Bedfordia?

5. What was your opinion of Bedfordia?

6. In what ways did you find Second Life useful for the task you were set, i.e. to have a project meeting?

7. In what ways do you think Second Life as a learning tool is different from BREO? [The university's Blackboard based content management system]

8. In what ways do you think Second Life could be used to support your learning?

From a cohort of 84 students 50 responses have been received. Note that only questions one and three give quantitative results while the other questions are of qualitative character. In question one for $80 \%$ of the respondents getting into Second Life was easy or neutral 20\% found it hard. The problems encountered by those $20 \%$ are about installing Second Life at home (which was not a requirement) or difficulties to register.

For question 3 only $3 \%$ of the students found it hard to find the island of Bedfordia (the student's home location) in Second Life. Those problems were not substantial and could be easily resolved by asking a tutor or friends (question 4).

The impression students got from the island Bedfordia (question 5) was overwhelmingly positive. Students commented with words like "exciting", "well designed", "interesting" or "pleasant". It seems here that the fact that the island has been landscaped by 
a skilled Second Life builder has been paid off. It is our feeling that professional landscaping is a nonnegligible factor when designing an official presence in Second Life. It facilitates students to accept the virtual world as "theirs", as a professional service of the university designed to enhance their teaching.

Question 6 "In what ways did you find Second Life useful for the task you were set, i.e. to have a project meeting?" suggests a more subtle picture. Many remarks were enthusiastic, however for reasons that are essentially generic to any software that supports virtual meetings. One of the critical answers put it to the point: "I could see nothing that Second Life did that an instant messenger could not.", or similarly "Since there are many communication softwares on the market, in my opinion for a virtual project meeting I would choose another software. [...]". Still, the majority was willing to freely assume the usefulness of Second Life as a proper tool for virtual meetings. It seems odd that the obvious overhead like registering, creating an avatar and learning basic moves has largely not been seen as an obstacle by most of the respondents. It may also be surprising that not a single response somehow addresses the issues that one's identity in Second Life is presented by an avatar and that a meeting by such proxy-identities might be perceived somehow differently then a (virtual) meeting where participants identify themselves by their real name.

Question 7 evaluates the student's perception of Second Life as a learning tool. In particular it has been asked to compare Second Life to the university's Blackboard type content management system. Many differences have been highlighted such as "Second Life is more interactive" or "Second Life is a real time experience and is fun" and virtually no similarities have been identified by any of the students. The response "Personally I wouldn't call it as a learning tool, but more of virtual excitement game." is an example typical to many of the student responses. This is interesting in view of the statement we quoted in the introduction " $[. .$.$] virtual world technologies pro-$ vide a [...] support in a superior way to the current Web 2.0 platforms such as Blackboard or Moodle." (Kingsley, 2007). If this were truly the case, wouldn't we expect that at least some of those who now had experience in both Blackboard and Second Life see some potential there?

Finally, Question 8 asks how Second Life would enhance one's learning experience. Here the answers are rather negatives "can't think of any way in which it may be used to support my learning." and similarly "Not useful because you can only use it for discussions and getting to know purposes, and not learning lecture notes for example.”. If at all, the usefulness of Second Life as a meeting tool has been highlighted, essentially in reference to answers given already to Question 6.

In summary the questionnaire suggests a certain openness towards the use of Second Life in general. In particular there were hardly any difficulties with the enrollment process or any issues with the concept of having an avatar in Second Life as part of an assessment task. Students in general felt positive about the island of Bedfordia and how it was built. However the answers to questions 7 and 8 made it painstakingly clear that they didn't see any relevant connection between Second Life and an electronic learning platforms such as Blackboard. The perception seemed rather that of a "game" that added some interesting colour to their teaching experience.

\subsection{Interview Results from the Building Activity}

Feedback from the second activity that required the actual built of structures in Second Life (see Section 3.3) has been gathered by conducting interviews. In each interview session approximately ten students took part and a recording device has been used to provide transcripts of the interviews. We structure the following sections around the main topics that have been addressed during those interviews.

\subsubsection{Students getting signed up to Second Life}

Most of the students had little difficulty signing up to Second Life: However this operation appeared to occur continuously throughout the activity. First, many of the groups assigned one or two persons to be responsible for the development of their group's showcase within the island. Towards the end of the project many of the other group members decided that they wanted to review the progress personally (i.e. with their own avatar within Second Life), or to in some way aid the development of the showcase. This sudden rush which coincided with the nearing project submission date caused issues with our ability to respond. At one point over 40 instant messages have been received in one day and considerable time was spent trying to deal with "confused" students who wanted to build a showcase, but clearly were not aware that their fellow group members had already built substantial structures. 


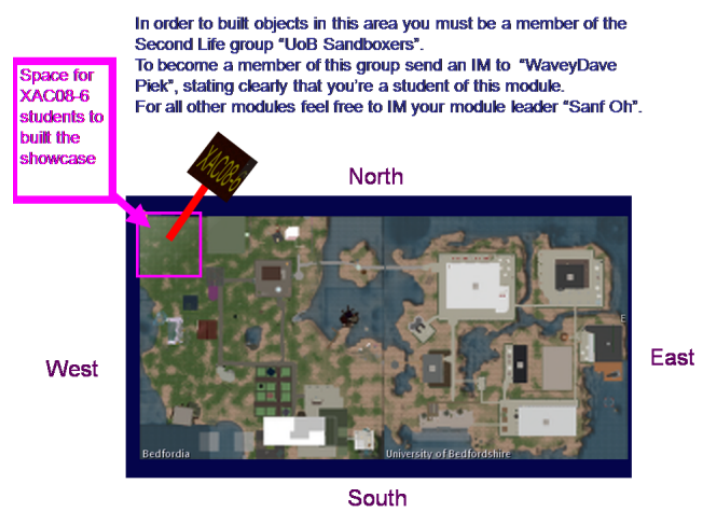

Figure 3: Instructions given to students where to find the building place.

\subsubsection{Instant messaging, but instead adding as a friend}

Our students had problems using the Second Life interface to send instant messages. Initial instructions indicated that students would need to message a member of staff (Figure 3). However many of the students thought that to send an instant message they needed to be friends with the staff member. Friend requests formed a substantial part of the traffic sent to the inbox of staff.

\subsubsection{Students navigating around Second Life}

Many of the students found the initial orientation island useful but a little confusing. The comments we received seemed to suggest that students would need much support in the way of building and learning how to build items within Second Life. However most were able to operate within the environment without too many problems.

\subsubsection{Finding space to build and 'prim' space availability}

Many of the students had problems with finding an area to build within the designated area. Most of these issues stemmed from students arriving very close to the submission deadlines to build their showcases. We had to make suggestions and in some cases changes to more capacious structures. Some groups elected to build skyboxes to ensure that they would not interfere with spaces closer to the ground. Towards the submission date we also found that the space on the island had run out of prim space ("prims" are the smallest building units that can be used to set up structures within Second Life. Essentially the number of prims that can be used on any given land is limited). Extra space had to be added.
Rather fascinatingly students perceived that their showcase buildings needed items like roofs, stairs and even chairs. During interviews it transpired that students thought the buildings needed to "look like proper buildings" otherwise they would not get marks for their project. We took opportunities to question students about the addition of items such as chairs, and in one case a coffee maker, it appeared that the students wanted to create a truly personalized experience for those visiting the showcase.

\subsubsection{Miscellaneous Issues}

Aside from the main issues addressed in the previous sections feedback also included the ability to undertake project meetings regardless of geographical location, the potential for creativity and use of imagination, and the contrast to other projects. Considerations over appearance include appropriate dress and indicates that students typically identified themselves with their avatar: "'Furies and animal avatars' are weird - people should be dressed in their own gender". Some benefits were suggested in relation to an international audience: "If people from different cultures and background wanted to work together Second Life would provide an excellent tool. In real life you have to be able to understand others' accents etc. Second Life has text chat which makes this process easier." Students had difficulties with some typical Second Life efforts such as learning to build and upload objects and textures, object number limits on Bedfordia, and obtaining the local in-world currency ("Linden Dollars").

Use of Second Life does not avoid the familiar group project difficulties - motivating group members (to build), and trying to better understand the requirements of the project. On the whole the efforts run at Bedfordia have been well-received by the students.

\subsection{Administrative and Technical Issues}

In this section we highlight some issues that have been identified by the educators complimentary to student feedback.

- Usability issues: To make a build it was necessary to enrol students in a Second Life group, the instructions as shown in Figure 3 have been distributed to the students. This enrollment procedure has been felt to be too time consuming. For further activities a process to streamline access of student groups to land in Second Life needs to be identified.

- Student guidance: Students needed more guidance then expected. Although Second Life is full 
of structures set up by non-IT professionals and hence postgraduate students in computing degree could be expected to acquire the necessary skills and knowledge themselves, it quickly turned out that some basic guidance needed to be provided.

- Updates: Second Life requires frequent updates of the client software. As student accounts are typically limited and the update requires administrator rights, this regular procedure implied a considerable additional workload to technical staff.

- Backups: The assessment process heavily depends on the availability of Second Life being accessible in a stable and reliable way. Hence there is an inherent risk of data loss, essentially not controllable by the university, that might have spoiled the structures set up by the students. It has been tried to safeguard against such an incident by regular in-world visits of the tutor. During those visits screenshots have been made to document student progress. Luckily no such incident occurred.

\section{CONCLUSIONS}

The students found the experience mostly positive or were at least neutral. Even students without an aptitude towards virtual worlds or "computer games" developed a sense of professional identity with their avatars. The production of a showcase provided them with a sense of ownership and achievement. Learning outcomes that address responsible and professional behavior in virtual environments have been met.

However from the administrative point of view a number of problems have been encountered and there is a feeling that accommodating those large student groups in Second Life is still very resource intensive. A straightforward and manageable process to ease controlled enrollment and to provide students with land to build on still needs to be identified.

An issue that remains essentially unresolved is the lack of a backup process that would facilitate a fair marking of the students work in case of a system failure.

Second Life enthusiasts often emphasize the suitability of that virtual world for education, but identify the steep learning curve for the students concerning basic steps on how to create, design and use their avatar as the main obstacle. While there are some minor issues when it comes to creatively building structures such a view merely hides the real, resource intensive, problems concerning enrollment and managing land accessibility. We have found that students are generally willing and ready to adopt a virtual presence within Second Life as part of their module diet. It is Second Life itself that has still to mature technologically to allow smooth management of large numbers of students.

However in view of ongoing research in this area, to name only the SLOODLE (Kemp and Livingstone, 2006) project at the University of Edinburgh that aims to integrate Second Life with the "traditional" content management system MOODLE, it can be envisaged that the technological difficulties will be overcome eventually and that Second Life will play a more prominent role in the educational sector in the future.

\section{ACKNOWLEDGEMENTS}

The authors want to thank the students of the University of Bedfordshire for their willingness to embark with the authors on this journey. Without them this work would not have been possible. We also want to thank Yucca Gemini (Second Life avatar name) who so beautifully landscaped the island of Bedfordia creating a stimulating atmosphere.

\section{REFERENCES}

Conrad, M., French, T., Maple, C., and Zhang, S. (2006). Preparing computing students for culturally diverse e-mediated it projects. Interactive Technology and Smart Education, 3(3):186-195.

Kemp, J. and Livingstone, D. (2006). Putting a Second Life "Metaverse" Skin on Learning Management Systems. Proceedings of the Second Life Education Workshop at SLCC, San Francisco, pages 13-18.

Kingsley, J. (2007). Time for educators to get a (second) life? EFMD Global Focus, 2(3):42-43.

Kirriemuir, J. (2008). A spring 2008 snapshot of uk higher and further education developments in second life.

Linden Lab (2003). Second life. http://secondlife.com.

Ritzema, T. and Harris, B. (2008). The use of second life for distance education. J. Comput. Small Coll., 23(6):110-116.

Salomon, M. (2007). Business in second life: an introduction. White paper, Smart Internet Cooperative Research Centre.

Sanchez, J. (2007). Second life: An interactive qualitative analysis. In Crawford, C., Willis, D. A., Carlsen, R., Gibson, I., McFerrin, K., Price, J., and Weber, R., editors, Proceedings of Society for Information Technology and Teacher Education International Conference 2007, pages 1240-1243, San Antonio, Texas, USA. AACE. 